\title{
A Spiral-ADDIEE \& R Industry-oriented Technology Course Development Model
}

\author{
Kai-Chao Yao, Wei-Tzer Huang, Cheng-Lung Lin \\ Department of Industrial Education and Technology \\ National Changhua University of Education, No.2, Shi-Da Road \\ Changhua City 50007, Taiwan, R.O.C
}

\begin{abstract}
A spiral-ADDIEE\&R model is introduced and utilized to develop, implement and evaluate an industry oriented technology course, automatic measurement technology. A process is built to develop teaching material and training device. The practical competence indicators for automatic measurement technology will be found using the Delphi questionnaire answered by industrial supervisors, engineers and university scholars. The teaching material contains 6 chapters and 27 sections for developing and a multi-functional automatic measurement platform that includes over 20 kinds of sensors and measurement devices, designed and constructed for student training use. An experimental class is given with assessment performed for examining the flaws in this course development process.
\end{abstract}

Keywords-industry-oriented; course development; automatic; measurement; experimental class; assessment

\section{INTRODUCTION}

Automatic measurement technology has specific requirements and manpower cultivation for industrial circles. The study is aimed at examining automatic measurement technology competence indicators to assist students with effective learning by fitting automatic measurement technology for industry oriented needs [1]. The software is the major issues for implementation into automatic measurement technology classes. Teaching material and training devices are additional problems that need to be addressed.

Labview is the most often use soft ware in the industry automatic measurement field [2]. It provides powerful functions for instrument control and measurement. Furthermore, automatic measurement technology application is considerably widespread in the automobile industry. Previously conventional manpower was used to carry out measurement and inspection. This was extremely time-consuming. LabVIEW is presently used for automotive ECUs and mechanical components to proceed with simulation, measurement and inspection of related functions.

\section{MAIN RESULTS}

Some scholars' research results are generalized about curriculum planning and teaching material development models. The proposed the spiral-ADDIEE\&R model is divided into six processes, including Analysis: literature analysis, demand analysis, and expert consultations; Design: the framed curriculum syllabus, curriculum planning, the establishment of thematic unit, content outline as well as lessons/time, the chapter plan of teaching material, and the design of teaching plan; Development: techniques \& experiments, the compilation of demonstrative teaching material modules, the submission of journal or conference papers, expert evaluations, the developmental scales, and the pilot test; Implementation: this stage was an experimental instructional design which assorted the scale to carry out the pretest-posttest control group design of quasi-experimental design; Evaluation: is based on the teaching performance assessment of the cognitive, psychomotor, and affective dimensions for Bloom's theory; However, "E \& R" was constantly proceeding the "Examination" and "Revising" towards the construction of curriculum and teaching material. Figure 1 shows the flow chart of the development process, Spiral- ADDIEE\&R Method.

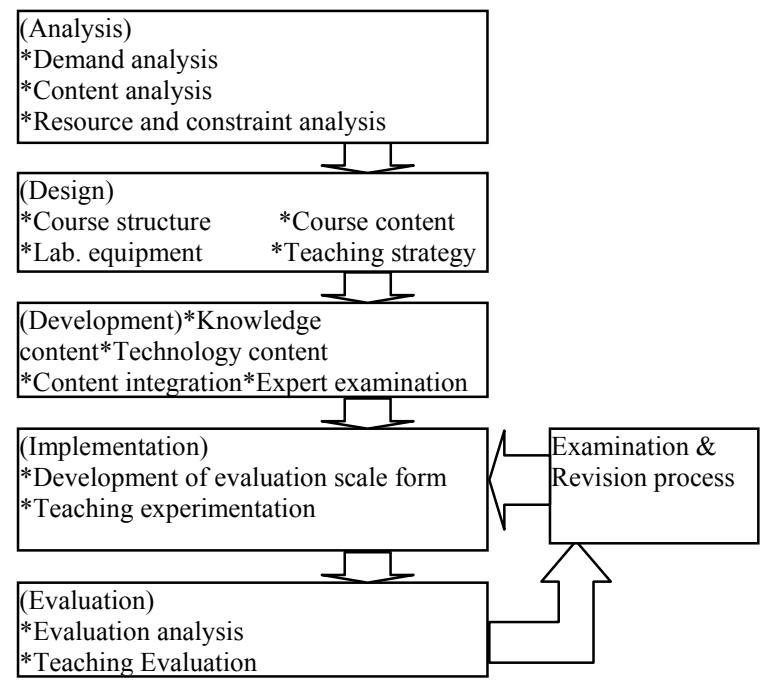

FIGURE I. THE FLOW CHART OF THE DEVELOPMENT PROCESS, SPIRAL-ADDIEE\&R METHOD

The methods used in this study included literature analysis, expert consultations, Delphi technique, experimental class and bloom evaluation theory. The following steps were carried out: (A) Literature Analysis Method; (B) Expert Consultations; (C) Delphi Technique; (D) Course design; (E) Automatic measurement platform establishment; (F) Develop evaluation forms; (G) Experimental class implementation; (H) Experimental class evaluation; (I) Examination and Revision process [3]-[5]: 


\section{A. Inquire Into Relatively Domestic and Overseas Documental Data}

The data was collected about automatic measurement, curriculum planning, and practice teaching material. We used the teaching material principles and development models to provide Delphi questionnaire and expert consultations for literature analysis and generalization.

\section{B. Conduct Expert Consultations for Initial Interview Guide}

This study seeks to understand the practical competence indicators for AMTC, developing a Delphi questionnaire using interview results answered by industrial supervisors, engineers, and university scholars. The following procedure was carried out for expert consultations. (1) Send out interview invitations and identify a list of interviewees; (2) Develop initial interview guide; (3) Carry out the interview seeking practical competence indicators for AMTC; (4) Modify and confirm the practical competence indicators for AMTC.

\section{Execute the Survey Using the Delphi Technique for Industry Needs}

Delphi questionnaire that adopted a 5-point Likert-type scale (i.e. a scale of 1 to 5) from "Not Important" to "Most Important" and designed open-ended questions that allowed experts to provide opinions will be developed using the literature review analysis and generalization and the expert interviews. We asked and confirmed ten experts to accept the Delphi survey. They were sent e-mail messages to offer opinions about practical competence indicators [6]-[9].

\section{Course Design}

The Kolmogorov-Smirnov one sample test was carried out using the third Delphi questionnaire for data analysis. We identified the consistency degree of ten expert opinions regarding practical competence indicators for the AMTC. In order to improve the teaching syllabus and teaching material unit design we adopted the spiral-ADDIEE\&R instructional design model. The Delphi survey results divided the practical competence indicators into six dimensions for AMTC: 1. Virtual instrument with four competence indicators. 2. LabVIEW programming design with eight competence indicators. 3. Interface of signal transmission with four competence indicators. 4. Sensing and measuring devices with four competence indicators. 5. Automatic measurement with three competence indicators. 6. Automatic measurement applications with four competence indicators. There are totally 27 competence indicators to be developed using the constructive method into a set of suitable teaching materials. An automatic measurement platform is also constructed for practical training use based on dimension five.

\section{E. Automatic Measurement Platform Establishment}

The multi-functional device measurement platform provides over 20 kinds of sensors and measurement devices for users. The DAQ-Card acquires data from every sensor and converts into physical signals for further processing by NI LabVIEW. The sensors and measurement devices are classified and interface easily with the corresponding function. It contains: (1) Infrared joules switch; (2) Weight sensor; (3) PD100; (4) AD590; (5) Humidity sensor; (6) Solar cells; (7) V / F converter; (8) Pressure sensor; (9) LVDT; (10) Rotary angle sensor; (11) Hall current; (12) Light type switch; (13) Machinery; (14) Ultrasonic; (15) Magnetic sensor; (16) Proximity switches; (17) Metal sensing; (18) Resistance class; (19) Microphone; (20) Liquid level controller; (21) Gas / Fumes concentration sensor; (22) Alcohol sensor.

\section{F. Develop Evaluation Forms}

A cognitive test, affective scale form, and psychomotor scale form were developed for experimental class assessment.

Ninety questions are given in the cognitive pilot test. The examination assesses expert validity containing dimensions for knowledge, comprehension, application, analysis, synthesis and evaluation. The students who take the test have basic Labview programming ability and are juniors in the Department of Industrial Education and Technology, National Changhua University of Education. Thirty six questions were deleted with 54 questions remaining in the difficulty and discrimination analysis index. Applying distraction and inspecting the questions using two-way specification table, 50 questions were chosen to construct a cognitive examination index. Utilizing KR-20 to inspect reliability, the value reaches .864 which is very reliable.

In assessing skill performance, a programmable virtual instrument skill ability assessment was used designed by Kai-Chao Yao and Hsiao-Mei Cheng in 2008 [10]. Its reliability was inspected with a value of .865 . There are four dimensions in the assessment form that are equipment assembling ability, virtual instrument operation ability, circuit wiring ability and programming ability. A 5-points Likert scale is used in every dimension for assessment.

An affective scale form was developed using expert opinions for the affective domain. The content has four dimensions: learning demand, cognitive development, skill performance and self exploration. There are 7 questions each dimension for a total of 28 questions. After item analysis, these 28 questions are all kept. The Cronbach $\alpha$ reliability test was applied in the pilot test with the value $\alpha=.928$.

\section{G. Experimental class implementation}

The class is offered as a required in 2011 fall and 2012 spring semester in the Department of Industrial Education and Technology, National Changhua University of Education, Taiwan. This course is named Automatic Measurement Technology for 3 hours and 3 credits. There were totally 43 students enrolled.

\section{H. Experimental Class Evaluation}

A quasi-experimental design is applied in the teaching experiment because the teaching materials and equipments were newly developed, Pre-test and post-test design methods were used in this course evaluation [11]. B. S. Bloom proposed taxonomy for educational objectives in 1956 [12]. According to this theory the evaluation involved three domains. The evaluation forms that were developed and designed were the cognitive test, affective scale form and psychomotor scale form. Figure 2 shows the schedule for formally evaluating the three domains. These three evaluation tools can be designed and developed during the Develop and Implementation phases. 


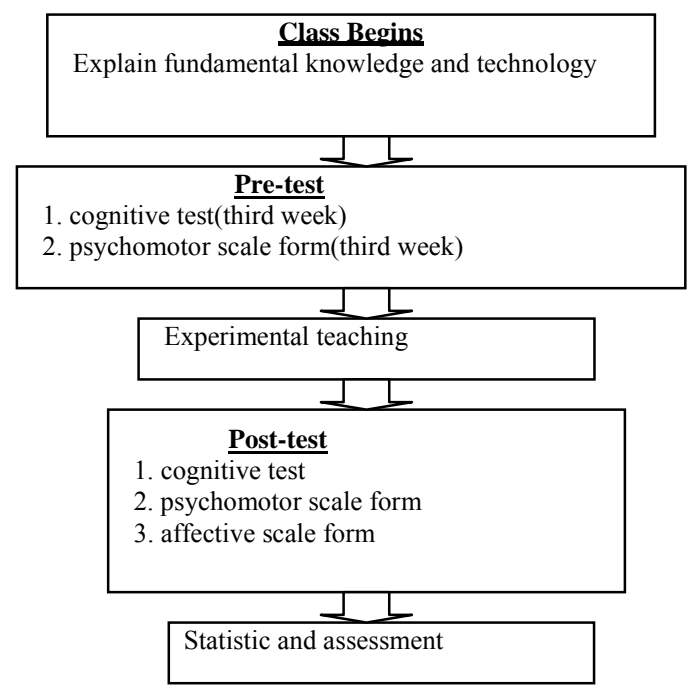

FIGURE II. THE SCHEDULE OF FORMALLY EVALUATING THE THREE DOMAINS

\section{Examination and Revision process}

Three assessment tests are conducted during the experimental class. The cognitive test result tells how effective the developed teaching materials and teaching equipments enhanced students cognitive ability. The psychomotor test result tells how much growth occurred in student skill. The affective questionnaire reflects how students feel about the course in learning demand, cognitive development, skill performance and self exploration. Based on the assessment of these three dimensions, the teaching material, teaching equipment, teaching method and so on can all be adjusted for the students' needs.

\section{III.CONCLUSIONS}

The evaluation results of this industry-oriented technology course, automatic measurement technology, constructed by this spiral-ADDIEE\&R model is shown below in three domains:

\section{Professional cognitive domain}

In the cognitive post-test performance, utilizing constructive teaching material, the post-test was a lot better than the pre-test. According to the t-test results the developed teaching material and teaching equipment help students perform well in the cognitive test. The analysis results show an obvious difference between the pre-test and post-test.

\section{Skill performance domain:}

In the psychomotor post-test performance, with developed teaching material and training equipment, utilizing constructive teaching strategy, the post-test was a lot better than the pre-test. According to the t-test results, the constructive teaching strategy helped students perform well in the psychomotor test. The analysis results showed an obvious difference between the pre-test and post-test.

\section{Affective domain}

(1) In the learning demand dimension the teaching material content is correct and easy to read. It presents a well organized, logical arrangement with enough knowledge and practices. The experimental parts of the teaching material clearly explain the experimental process.

(2) In the cognitive development dimension the goal of each chapter clearly expresses the key learning points. The teaching material corresponds with the experimental equipment and both inspire me to develop new products.

(3) In the skill performance dimension the course and teaching material excite me to learn Labview programming and promote my knowledge and skill in understanding the computer measurement instrument structure.

(4) In the self exploration dimension most of the students who take this course think the course contains professional automatic measurement technology skill training. This course matches THE skill needs of the automatic measurement technology industry. Moreover, this course offers a personal professional advantage for future jobs.

\section{ACKNOWLEDGEMENT}

This study was funded by a grant provided by the ministry of science and technology, Taiwan, under the grant number MOST 103-2511-S-018-016.

\section{REFERENCE}

[1] Sidorenko, T.V., Information technologies as a tool in development of focused professional skills of technical students. Vestnik of Tomsk State University, 309, pp. 68-69, 2008.

[2] Kai-Chao, Yao, Jiunn-Shiou Fang and Wei-tzer Huang, "Multi-function Automatic Measurement Platform ", International Journal of Innovative Computing, Information and Control (IJICIC), Vol 8, No. 11, pp. 76637678, Nov. 2012.

[3] Sidorenko, T.V., Information technologies as a tool in development of focused professional skills of technical students. Vestnik of Tomsk State University, 309, pp. 68-69, 2008.

[4] Tanner, D. \& Tanner, L, Curriculum development: theory into practice. Englewood Cliffs, New Jersey: Merrill, an imprint of Prentice Hall, 1995.

[5] Kemp, J. E., The instructional design process. New York: Haper and Row, 1985.

[6] Guan, S.R. and Shiu, Y.J., First visit of developments of professional competence indicators of the cultural creative industry - take staffs of digital media planning for the example. Proc. of 2007 Cultural Creativity and Innovative Design Academic Conf. Transworld Institute of Technology, 2007.

[7] Spencer, L.M. and Spencer, S.M., Competence at Work. New York, NY: Wiley, 1993.

[8] Gonczi, A., Hager, P. and Oliver, L., Establishing competency-based standards in the professions. Canberra: Department of Employment, Education and Training, 1990.

[9] Scott, M.J., AICPA competency model for the new finance professional. The CPA J., 68, 10, pp. 40-45, 1998.

[10] Kai-Chao Yao, Hsiao-Mei Cheng, "Teaching Evaluation of Psychomotor Domain and Practical Example ", Journal of Industrial Education and Technology, Vol. 33, pp. 81-100, Dec. 2008.

[11] Robert Y. Cavana, Brian L. Delahaye, Uma Sekaran, Applied Business Research:Qualitative \& Quantitative Methods 1st edition: John Wiley and Sons Ltd, 2001.

[12] Bloom, B. S., Taxonomy of Educational Objective. NY: David Makay Company, 1956

[13] Course inquiry system of UCUE, https://aps.ncue.edu.tw/qry_course.php 